\title{
Development of a state wide tobacco treatment specialist training and certification programme for Massachusetts
}

\author{
Lori Pbert, Judith K Ockene, Beth M Ewy, Ellen Sachs Leicher, Donna Warner
}

University of

Massachusetts Medical

School, Division of

Preventive and

Behavioral Medicine,

Worcester,

Massachusetts, USA

L Pbert

J K Ockene

B M Ewy

ESL Associates, Inc E S Leicher

Massachusetts Tobacco Control Program, Massachusetts

Department of Public

Health

D Warner

Correspondence to: Lori Pbert PhD, University of Massachusetts Medical School, Division of

Preventive and Behavioral

Medicine, 55 Lake Avenue

North, Worcester, MA

01655, USA;

lori.pbert@umassmed.edu

Received 11 October 1999 and in revised form

31 May 2000. Accepted 5 June 2000

\begin{abstract}
Objective-To describe the research conducted to structure and develop a statewide tobacco training and certification programme for tobacco treatment specialists (TTSs) in Massachusetts.

Design-Qualitative research strategies were used to obtain information on certification development and opinions regarding TTS training and certification from key informants. A role definition and validation study was then conducted to determine the core competencies for TTSs. A comprehensive training programme was developed, piloted, and finalised, and a certification programme was initiated.
\end{abstract}

Participants-Key informants included: individuals involved in the development of their professional certification programmes; tobacco treatment providers from across Massachusetts; and national tobacco treatment experts.

Main outcome measures-Participants' opinions about the need for and structure of a training and certification programme for individuals specialising in the provision of moderate to intensive tobacco treatment; delineation of core competencies for TTSs, using the Agency for Health Care Policy and Research (now the Agency for Healthcare Research and Quality) clinical practice guideline as a foundation for the development of evidence based standards of practice for the treatment of nicotine dependence.

Results-The data support a comprehensive training and certification programme for TTSs in Massachusetts. Main concerns include the cost of obtaining certification, the potential to exclude uncertified healthcare professionals from delivering basic tobacco treatment, and the role of the TTS in the healthcare delivery system and the community. The training programme developed for Massachusetts was piloted, and the structure of a statewide training and certification programme for TTSs was finalised.

Conclusions-The research provides support for the need and acceptance of a training and certification programme for TTSs in Massachusetts, and presents the challenges to be addressed. We demonstrated the feasibility of developing and implementing an evidence based training programme, and of initiating a statewide certification programme in Massachusetts. This work will add to a national dialogue on the development of a training and certification programme for tobacco treatment providers and encourage further research into the potential impact of statewide and national certification. (Tobacco Control 2000;9:372-381)

Keywords: certification; tobacco treatment; training; Massachusetts

Tobacco use, responsible for nearly one in five deaths, is the leading preventable cause of morbidity in the USA. Its annual cost to the nation is $\$ 50$ billion in direct healthcare costs ${ }^{1}$ and billions more in lost productivity. Even though the hazards of tobacco use are well known, 48 million adult Americans currently smoke cigarettes ${ }^{2}$ and another 5.3 million adults use other forms of tobacco, ${ }^{3}$ making tobacco use an important public health and treatment priority.

Brief intervention provided by primary care providers is effective and could double the nation's quit rate. ${ }^{4}$ However, many tobacco users need more intensive treatment, and a review of the tobacco treatment literature indicates that more intensive treatment of greater than 10 minutes duration over multiple treatment sessions is more effective than brief advice. ${ }^{4}$ Consistent with this finding, the "Best practices for comprehensive tobacco control programs" document produced by the Centers for Disease Control and Prevention in $1999^{5}$ recommends identification of and advice to smokers, provision of brief counselling, and a full range of treatment services including pharmaceutical aids, more intensive behavioural counselling, and follow up visits. These recommendations are consistant with those of the Agency for Health Care Policy and Research (AHCPR) smoking cessation clinical practice guideline, ${ }^{4}$ which has been recently updated as the Agency for Healthcare Research and Quality (AHRQ) guideline. ${ }^{6}$

Unfortunately, health services, plans, and organisations generally lack individuals with the training and expertise needed to provide effective, moderate to intensive, evidence based treatment for tobacco users. The recommendations of a national ad hoc committee set up to address tobacco dependence noted that "State and national tobacco control policies must address the need to make effective treatments available to the widest possible group of 
tobacco users", ${ }^{7}$ and that the development of a training and certification or licensing programme for providers specialising in tobacco treatment will help assure the delivery of effective evidence based treatment to those tobacco users who need more intensive intervention than healthcare professionals can provide in the course of delivering routine care. At the time of the report, the Commonwealth of Massachusetts had been in the process of developing and pilot testing such a programme. The recommendation made by the ad hoc committee acknowledges that the complexity and intensity of tobacco treatment needs to be matched to the needs of the tobacco user. This is consistent with the model proposed by Abrams and colleagues ${ }^{8}$ recommending a comprehensive stepped care approach for the treatment of nicotine dependence. Thus, tobacco users requiring minimal assistance may be best served by receiving brief intervention from physicians, nurses, and other healthcare professionals within the course of routine healthcare contact, following the evidence based 5As model recommended by the AHRQ (formerly the AHCPR). ${ }^{6}$ Tobacco users with more complex issues related to their dependence may require more intensive, specialised treatment with follow up by tobacco treatment specialists (TTSs) in community health centres, hospitals, healthcare, and social service agencies, utilising evidence based strategies recommended by AHRQ for tobacco treatment specialists. And lastly, the complicated tobacco users who may be clinically depressed or alcohol dependent may be best served by doctoral level or licensed alcohol and drug addiction and mental health providers who can offer intensive treatment for drug dependence and/or mental health concerns in conjunction with treatment for tobacco dependence. It is the provider of moderate to intensive, specialised tobacco treatment services who is targeted for training and certification as a TTS by the programme described in this paper.

Since 1993, the Massachusetts Tobacco Control Program (MTCP) has funded tobacco treatment providers through the Massachusetts Department of Public Health (MDPH) to provide treatment services to tobacco users in Massachusetts. Over the years, tobacco treatment providers, MTCP, and state vendors providing support to tobacco treatment programmes have expressed concern regarding a lack of comprehensive training for tobacco treatment providers, and a lack of standards of practice and consistency in the quality of tobacco treatment services delivered throughout the state. In an effort to improve the quality of tobacco treatment services delivered in Massachusetts and establish standards of practice for the delivery of moderate to intensive treatment services within healthcare agencies, the MTCP contracted with the University of Massachusetts Medical School (UMMS) in 1997 to develop a comprehensive statewide tobacco training and certification programme. This paper will describe: the research conducted to guide and inform the development of such a programme; the role definition and validation study used to determine the core competencies for TTSs; and the comprehensive TTS training, evaluation, and certification programme that was developed as a result of this research. This paper also will frame key issues regarding the development of a training and certification programme for providers specialising in the delivery of intensive tobacco treatment, who should be targeted for certification, what additional research is needed, and whether such a programme should be state based or national.

\section{Methods and results}

Initial research into the feasibility of and interest in developing a statewide training and certification programme for TTSs in Massachusetts was conducted between September 1997 and March 1998. A role definition and validation study was then conducted to define the core competencies needed by TTSs in order to effectively carry out their job functions. This research was conducted in three phases: I. Literature review and professional certification expert interviews; II. Massachusetts tobacco treatment provider interviews and survey, and national tobacco treatment expert interviews; and III. Role definition and validation study. The methods used and results of each phase are described.

PHASE I: LITERATURE REVIEW AND PROFESSIONAL CERTIFICATION EXPERT INTERVIEWS

Methods

A thorough literature search was conducted on the development of certification programmes and related issues published for the following health related professions: certified health education specialists, school health educators, diabetes educators, gerontological counsellors, social workers, addictions counsellors, rehabilitation counsellors, and mental health counsellors. For each profession, the following was summarised: the process by which they developed and implemented their certification programme, benefits and concerns regarding certification, the process by which core competencies were determined, and the requirements for certification. The literature search resulted in 70 citations from the following databases: Medline, CINAHL, HealthSTAR, ERIC, and PsychInfo. Upon thorough review of the citations, 27 articles and/or books were selected for retrieval and review.

Next, a qualitative research strategy was used to obtain information regarding various aspects of the certification development process from 11 key informants who had been involved in the development of their health related professional certification programmes: American Red Cross CPR, American Psychological Association practitioner, masters addiction counsellor, certified addiction specialist, certified rehabilitation counsellor, certified health education specialist, certified alcohol and drug abuse counsellor, and medical interpreters (in process at the time of the interviews). These individuals were interviewed by telephone using a standardised 
interview guide. The guide contained nine multi-part questions covering the following areas: motivation for the development of the certification, the development process including problems encountered and lessons learned, eligibility requirements, establishment of core competencies, recertification requirements, and initial professional reaction to certification.

\section{Results}

The literature search identified no published articles on the subject of tobacco use treatment training and certification, as was expected. However, it did help identify organisations which have addressed the issue of certification. Historical accounts of the development of the certification process provided recommendations for structuring the process. These included: task force development, curriculum guides and training material, nationwide workshops and "think tank" meetings, education/ work experience minimums, structure of the exam and evaluation process, recertification requirements, and legal issues. In addition, much of the literature was dedicated to discussing the benefits and liabilities of certification, concluding that the advantages are substantial but cautioning against overly severe restrictions. Overall, the addiction counsellors certification process most closely mirrors that of TTSs, with caregivers of varying professional backgrounds involved in the delivery of services. A major challenge identified for the certifying organisation is how to structure the training and certification process objectively to address the needs of these diverse groups. (For a partial listing of articles reviewed, see references ${ }^{9-19}$; for a complete listing, contact the corresponding author.)

Results of the professional certification expert interviews revealed some common key elements among the various certification programmes which served as a foundation for the development of the TTS certification programme. First, the respondents generally noted that certification was developed as a way of standardising practices and recognising professionals, with the focus being on the development of common practice standards. By obtaining certification, the individual joins a group of professional colleagues who have achieved a certain level of competency and have agreed to abide by a specified set of professional standards.

There was agreement that inclusion of well known experts in the field in the certification development process lends credibility to the final programme. In most cases, a planning committee was convened to oversee the development of the certification process, their members generally representing related professional organisations and educational institutions. Extensive pre-planning research on the profession itself and assessment of the need for certification contributed to the success of certification programme development. Planning included vocational assessment research, surveys, job analyses, development of professional and continuing education pro- grammes, and development of an examination. The data gathered in formative research were then used to develop core competencies and examinations. Owing to the significant time and resources needed in the preparation and organisation of the certification programme, they took, on average, up to two years to develop. Lack of adequate funding and personnel were frequently mentioned barriers to meeting the goals of their programmes. It was recommended that, throughout the planning process, the administrative requirements for the programme's various aspects (that is, examination, continuing education, and membership record keeping) be thought out early in the process and carefully addressed.

All credentialing programmes required some combination of education and experience and the passage of an examination to be eligible for certification. Many programmes incorporated flexibility in the requirements to allow candidates of various backgrounds to be eligible. "Grandfathering" was used in many programmes, whereby the candidate qualifies for certification initially based on education or experience in the field. Candidates for most of the programmes take an examination which assesses their knowledge of core competencies, job requirements, and standards of practice via a written multiple choice exam format. All organisations charge a fee and examinations are administered using either in house personnel or outside organisations. Recertification for members was required by all organisations with the frequency varying among the groups; all required continuing education hours. Proponents of certification felt it would provide recognition for their work, while those objecting questioned the credential's worth given the time and expense involved in obtaining it. According to those interviewed, most individuals who were initially opposed to certification, over time, generally came to accept the certification's credibility.

PHASE II: MASSACHUSETTS TOBACCO TREATMENT PROVIDER INTERVIEWS AND SURVEY, AND NATIONAL TOBACCO TREATMENT EXPERT INTERVIEWS

Methods

Based on the recommendations from the phase I research, a three part process for gathering opinions regarding the need for and structure of a training and certification programme for TTSs was instituted. First, 10 professionals providing tobacco treatment services in Massachusetts were selected to be interviewed regarding the need for certification of tobacco treatment providers. These individuals were initially identified as knowledgeable and exemplary tobacco treatment providers by MTCP regional field directors, and were chosen because they represented a variety of geographic locations, ethnic groups, and practice settings. These key informants were interviewed by telephone using a standardised interview guide which addressed the following topics: the need for certification, the pros and cons of certification for providers, how certification might be received by their employers, clients, and colleagues, eligibility 
Table 1 Demographics of persons responding to the initial Massachusetts tobacco treatment provider interviews and survey

\begin{tabular}{|c|c|c|}
\hline \multirow[b]{2}{*}{ Characteristics } & \multicolumn{2}{|c|}{$\begin{array}{l}\text { Respondent distribution } \\
(\%)\end{array}$} \\
\hline & $\begin{array}{l}\text { Interview } \\
(n=10)\end{array}$ & $\begin{array}{l}\text { Survey } \\
(n=82)\end{array}$ \\
\hline \multicolumn{3}{|l|}{ Sex } \\
\hline Female & 90 & 81 \\
\hline Male & 10 & 19 \\
\hline \multicolumn{3}{|l|}{ Age } \\
\hline Under 30 & 10 & 6 \\
\hline $31-40$ & 40 & 25 \\
\hline $41-50$ & 40 & 51 \\
\hline $51-62$ & 10 & 15 \\
\hline \multicolumn{3}{|l|}{ Education } \\
\hline High School & 0 & 6 \\
\hline Associate's & 0 & 10 \\
\hline Diploma RN & 10 & 0 \\
\hline Bachelor's & 60 & 49 \\
\hline Master's & 30 & 35 \\
\hline \multicolumn{3}{|l|}{ Experience in tobacco treatment field } \\
\hline$<1$ year & 0 & 18 \\
\hline $1-<3$ years & 20 & 31 \\
\hline $3-7$ years & 70 & 34 \\
\hline $7+$ years & 10 & 17 \\
\hline \multicolumn{3}{|l|}{ Work setting $\star$} \\
\hline Community health centre & 30 & 17 \\
\hline Hospital & 20 & 34 \\
\hline Community service agency & 20 & 39 \\
\hline Voluntary Agency (ALA, ACS) & 20 & 0 \\
\hline Self employed & 10 & 4 \\
\hline Boards of health & 0 & 9 \\
\hline Health maintenance organisation & 0 & 4 \\
\hline School system & 0 & 2 \\
\hline Group/private practice & 0 & 9 \\
\hline
\end{tabular}

*Percentages do not add up to $100 \%$, as some individuals work in multiple types of programs and settings.

ALA, American Lung Association; ACS, American Cancer

Society.

requirements for the TTS designation, core competencies, recertification, fees, and training.

Next, a written survey, modelled after the interview guides used with the professional certification experts and the 10 Massachusetts tobacco treatment providers, was developed to poll tobacco treatment providers in Massachusetts to determine their opinion regarding certification. Since, similar to other states, there was no structure or registry in Massachusetts to identify tobacco treatment providers, the survey population comprised MTCP providers, and American Lung Association and American Cancer Society facilitators. One hundred and twenty two potential respondents were identified and mailed the self administered 25 question survey. Eighty two completed surveys were received. The surveys were tabulated based on raw number frequency, cumulative frequency, and percentages for non-scaled items. Scaled items underwent analysis of mean, frequency, and range. Cross tabulation was conducted to ascertain whether work experience and education were related to attitudes toward certification. Sample and cell sizes were small in this analysis. Therefore, the findings from these surveys should be interpreted in conjunction with the results of other research performed.

Following the interviews and surveys of Massachusetts tobacco treatment providers, 18 individuals in the field of tobacco treatment were identified based on their national status as tobacco treatment experts. An interview guide, based on findings and key issues delineated from phase I and from Massachusetts tobacco treatment providers, was developed to elicit the opinions of the national experts regarding certification of tobacco treatment specialists. It contained 11 multi-part questions covering the following areas: the need for a certification process, levels of certification, benefits and drawbacks of certification, basis of certification, eligibility for certification, core competencies, and recertification. Interviewees were asked a series of open ended questions and prompted with suggested responses only when necessary.

\section{Results}

Table 1 shows the demographic breakdown of Massachusetts tobacco treatment providers who were interviewed and who completed the written survey. They included both MTCP funded and non-MTCP funded providers and represented a wide range of professionals, including nurses, health education specialists, substance abuse counsellors, licensed social workers, respiratory therapists, and hypnotherapists. The national experts included 12 tobacco treatment researchers and six who work in the area of health policy as it relates to tobacco treatment. All are nationally involved in addressing tobacco treatment issues and recognised by the literature and colleagues in the field.

Table 2 summarises the results from the Massachusetts tobacco treatment provider interviews, the Massachusetts tobacco treatment provider survey, and the national tobacco treatment expert interviews. Almost all respondents to the interviews and the survey noted anticipated benefits and a need within the industry to set standards of practice and provide evidence based, effective services. Cautionary notes regarding the time and financial cost of obtaining certification were stated by each group, and national experts expressed concern about potentially excluding some providers from certification or eliminating brief provider delivered treatment. In general there was agreement that candidates for certification should meet certain eligibility requirements and that the training curriculum should address a broad range of core competencies, including basic psychological concepts, counselling skills, behaviour modification theory, pharmacology and tobacco science, multiple addictions, and communication skills. Basic training should incorporate treatment of special populations, as most tobacco treatment counsellors provide services to a mix of clients.

All Massachusetts tobacco treatment providers who were interviewed indicated that a certification programme should be pursued, although several qualified their response with concern over the obstacles inherent in developing and implementing such a large scale effort (table 2). The majority reported support for certification and the belief that certification would improve provision of treatment services, establish professional practice standards, and legitimise the profession. A need for training was highlighted by this respondent group. 
Of the 18 national experts interviewed, 14 either reported there should definitely be a certification process (eight) or reported a qualified yes to certification (six) as long as certain concerns, such as limiting access to or restricting provision of service, were resolved. Of the remaining four interviewees, one thought additional research was needed to determine the value of certification, one felt strongly that there should not be a certification process, and the remaining two thought there might be merit in certifying the programmes that offer tobacco treatment services. Regarding levels of certification, there was great variability in response. Some thought there need only be a basic level of certification, while others thought there should be two or more levels of certification to allow for advanced level treatment for tobacco users who need more intensive intervention. A few respondents thought there need only be an advanced level of certification as basic tobacco treatment skills should be an integral part of healthcare providers' curricula.

PHASE III: CONVENING OF A STEERING

COMMITTEE, AND ROLE DEFINITION AND

VALIDATION STUDY

Methods

Specific recommendations for proceeding with the training and certification programme arose from the findings of phases I and II. The first was to establish a certification steering committee to oversee the development of a certification programme, and set the standards for the competencies required of specialists and for the quality and consistency of services they deliver. A certification steering committee, established and convened in May 1998, consisted of 19 persons representing community health centres, hospitals, substance abuse centres, voluntary agencies, the state health department, and state medical society; members were invited to participate on the recommendation of $\mathrm{MDPH}$.

The second recommendation was to conduct a role definition study to determine core competencies for TTSs. Defining the core competencies and skills necessary to perform a job is one of the first steps in establishing a certification programme. This is accomplished by interviewing those who currently work in the field as treatment service providers and then analysing and synthesizing the data from these interviews. A role definition and validation study was initiated in the fall of 1998. Fifteen statewide treatment specialists, recommended by the steering committee as being exemplary in their provision of tobacco treatment services, were interviewed individually regarding the functions and competencies of TTSs

Table 2 Certification issues summarised: results of Massachusetts tobacco treatment provider interviews and surveys, and national tobacco treatment expert interviews

\begin{tabular}{|c|c|c|c|}
\hline \multirow[b]{2}{*}{ Certification issue } & \multicolumn{3}{|l|}{ Results by data source } \\
\hline & Massachusetts provider interviewees & Massachusetts provider survey respondents & National experts \\
\hline $\begin{array}{l}\text { Should there be } \\
\text { certification for TTSs? }\end{array}$ & Yes (all); most would obtain & Yes (majority) & $\begin{array}{l}\text { Yes: } 14 / 18 \text { (definitely=8, qualified=6) } \\
\text { Need research: } 1 / 18 \text { No: } 3 / 18\end{array}$ \\
\hline Benefits & $\begin{array}{l}\text { - Standards of practice } \\
\text { - Credibility and professionalism } \\
\text { - Provision of effective services to } \\
\text { tobacco users } \\
\text { - Increased educational opportunities for } \\
\text { providers } \\
\text { - Job security and promotion potential } \\
\text { - Increased marketability of tobacco } \\
\text { treatment programmes } \\
\text { - Possible insurance reimbursement }\end{array}$ & $\begin{array}{l}\text { - Standards of practice } \\
\text { - Credibility, legitimise the profession } \\
\text { - Increase quality of care provided to tobacco } \\
\text { users } \\
\text { - Enhance career potential }\end{array}$ & $\begin{array}{l}\text { - Assure competency among tobacco } \\
\text { treatment providers and consistency of } \\
\text { services provided } \\
\text { - Ensure evidence based treatment } \\
\text { methodologies are utilised }\end{array}$ \\
\hline Concerns & $\begin{array}{l}\text { - Cost of certification } \\
\text { - Time commitment } \\
\text { - Need to be sensitive to cultural and } \\
\text { language differences }\end{array}$ & $\begin{array}{l}\text { - Cost of certification } \\
\text { - Time commitment } \\
\text { - Potential to restrict access to services }\end{array}$ & $\begin{array}{l}\text { - Administration of certification } \\
\text { programme } \\
\text { - Need to determine where TTS fits in } \\
\text { the healthcare delivery system } \\
\text { - Potential to restrict access to services } \\
\text { - Potential to exclude qualified } \\
\text { individuals }\end{array}$ \\
\hline Eligibility requirements & $\begin{array}{l}\text { - Experience in substance abuse and } \\
\text { tobacco treatment } \\
\text { - Some formal training } \\
\text { - No consensus re: minimum } \\
\text { educational requirements } \\
\text { - Examination (include essay section) }\end{array}$ & $\begin{array}{l}\text { - Length of experience in field } \\
\text { - Training in tobacco treatment } \\
\text { - Educational level not important } \\
\text { - 1/2 (5/10) endorsed passage of exam }\end{array}$ & $\begin{array}{l}\text { - Examination }(14 / 18) \\
\text { - Professional preparation and } \\
\text { experience (no consensus) }\end{array}$ \\
\hline Grandfathering & - Mixed response & - Overwhelmingly supported & - Majority $(11 / 18)$ said no \\
\hline $\begin{array}{l}\text { Recertification (exam, } \\
\text { CEUs) }\end{array}$ & $\begin{array}{l}\text { - Based on CEU requirement } \\
\text { - Every 2-3 years }\end{array}$ & - Based on CEU requirement & - Based on CEU requirement \\
\hline Levels of certification & $\begin{array}{l}\text { - Basic level and certification should } \\
\text { include special populations; not much } \\
\text { support for multiple levels of certification }\end{array}$ & $\begin{array}{l}\text { - } 1 / 2(5 / 10) \text { endorsed subspecialty certification } \\
\text { for co-morbid populations and the mentally ill }\end{array}$ & $\begin{array}{l}\text { - Basic level only }(6 / 18) \text {; emphasise } \\
\text { referral skills for complex clients } \\
\text { - Two or more levels }(6 / 18) \\
\text { - Advanced level only }(3 / 18) \\
\text { - Undecided }(1 / 18)\end{array}$ \\
\hline Training structure & $\begin{array}{l}\text { - Seminars or conferences } \\
\text { - Interactive, use case studies and small } \\
\text { group discussions }\end{array}$ & $\begin{array}{l}\text { - Local full day seminar format trainings } \\
\text { - Home study }\end{array}$ & N/A \\
\hline
\end{tabular}


Table 3 Demographics of persons serving on local role validation committee $(n=15)^{*}$

\begin{tabular}{lc}
\hline Characteristics & Distribution(\%) \\
\hline Sex & \\
Female & 87 \\
Male & 13 \\
Age $(\mathrm{n}=14)$ & 7 \\
Under 30 & 36 \\
$31-40$ & 29 \\
$41-50$ & 29 \\
$51-62$ & \\
Education (n=14) & 7 \\
Associate's & 7 \\
Licensed practical nurse & 7 \\
Diploma RN & 36 \\
Bachelor's & 36 \\
Master's & 7 \\
PsyD & \\
Experience in tobacco treatment field & \\
(n=14) & 0 \\
< 1 year & 0 \\
1-<3 years & 64 \\
3-7 years & 36 \\
7+ years & \\
Work setting & 33 \\
Community health centre & 27 \\
Hospital & 20 \\
Community service agency & 13 \\
Voluntary agency (ALA, ACS) & 7 \\
Self employed & \\
\hline
\end{tabular}

*Fifteen individuals participated on the local role validation committee. Demographic data, other than sex and work setting, was not available on one participant.

(see table 3 for demographics of the local role validation committee). These local experts were then convened to refine core competencies and the TTS skill profile.

In an effort to broaden our base and ensure that all aspects of the TTS role had been identified, an eight member panel of national tobacco experts known for their tobacco treatment research and/or provision of tobacco treatment services was convened to comment on the appropriateness of the core competencies, major responsibilities, and standards of practice derived from the role definition study. These experts were interviewed individually by phone using an interview guide similar to that for the local experts. In November 1998, a conference call with these national experts provided a final review of the core competencies and skill sets required of the TTS.

From this study emerged a listing of core TTS responsibilities and functions. These core responsibilities, competencies, and skill sets then underwent a validation study. This study was conducted in early 1999 and involved sending a written survey to the original set of Massachusetts tobacco treatment providers, asking for their feedback on the core TTS responsibilities and functions derived from the role definition study.

Results

From the role definition and validation study emerged a definition of the role of a TTS, as well as a listing of TTS core responsibilities and related skill sets and knowledge areas, which became the basis for a comprehensive TTS certification training curriculum. The role of a TTS, which was affirmed by $90 \%$ of the validation study respondents, was defined as follows: "To help tobacco dependent individuals eliminate or substantially reduce
Box 1 Tobacco treatment specialist core responsibilities as determined through the role definition study

- Provision of information and education

- Intake and assessment

- Treatment planning and implementation

- Pharmacotherapy support and guidance

- Counselling: individual, telephone, and group

- Monitoring and evaluation of individual progress

- Relapse prevention and recycling of relapsed clients

- Follow up and ongoing support

- Record keeping and programme reporting

- Referral services

- Professional development

-Serve as a resource to other professionals

-Remain up to date on new methods of quitting and other cessation related skills

their tobacco use by assisting them in developing the motivation, confidence, knowledge and skills necessary to achieve cessation and maintain abstinence."

Eleven core responsibilities were identified (box 1). While the results of the role validation study validated the original competencies overall, there was less support for a 12th competency, community outreach, that was ultimately excluded by the certification steering committee. The issue of community outreach has been a subject of debate throughout the role definition process. Individual treatment specialists may or may not need to do outreach, depending upon the environment in which they work. Although community outreach was excluded as a core function, the steering committee decided that it would be required as a continuing education course following certification.

Thirty knowledge and skill areas emerged from the original role definition study largely validating the role definition study. Respondents rated the importance of each skill and knowledge area to a training curriculum as either "must have", "nice to have" or "not necessary" (table 4). The high totals in columns 1 and 2 made a strong case for keeping all components as part of either a core training programme or a continuing education component. Based on the results of the role validation study, and in concert with the certification steering committee, the knowledge and skill areas were grouped according to content and became the basis for the development of our pilot training programme.

\section{Development of the training programme: core competencies}

Given one of the primary reasons for developing a training and certification programme was to establish a uniform, evidence based standard of practice for TTSs, the certification steering committee developed 11 practice 
Table 4 TTS skill and knowledge areas: importance to curriculum *

\begin{tabular}{|c|c|c|c|}
\hline Skill/knowledge area & $\begin{array}{l}\text { Must have } \\
(\%)\end{array}$ & $\begin{array}{l}\text { Nice to have } \\
(\%)\end{array}$ & $\begin{array}{l}\text { Don't need } \\
(\%)\end{array}$ \\
\hline Relapse prevention & 96 & 4 & 0 \\
\hline Health consequences of tobacco use & 96 & 2 & 2 \\
\hline Cessation methods and evidence of effectiveness & 95 & 3 & 2 \\
\hline Counselling individuals (face to face) & 92 & 7 & 1 \\
\hline Group counselling & 92 & 7 & 1 \\
\hline Addiction theory & 89 & 10 & 1 \\
\hline Nicotine addiction specifics & 87 & 13 & 0 \\
\hline Counselling theory, process, and ethics & 86 & 13 & 1 \\
\hline Stages and process of change & 85 & 14 & 1 \\
\hline Intake and assessment & 85 & 11 & 4 \\
\hline Treatment plan development & 84 & 13 & 3 \\
\hline Brief intervention and referral & 74 & 20 & 6 \\
\hline Counselling individuals (telephone) & 70 & 22 & 8 \\
\hline Working across sex, race, and culture & 67 & 30 & 3 \\
\hline Promoting wellness and healthy lifestyles & 66 & 33 & 1 \\
\hline Programme evaluation & 64 & 35 & 1 \\
\hline Working across socioeconomic differences & 64 & 34 & 2 \\
\hline Working with youth & 62 & 38 & 0 \\
\hline Aftercare & 62 & 34 & 4 \\
\hline Referral & 62 & 34 & 4 \\
\hline Basic pharmacology & 61 & 36 & 3 \\
\hline Pharmacotherapy & 58 & 37 & 5 \\
\hline Working with elders & 54 & 45 & 1 \\
\hline Managing your own professional development & 53 & 40 & 7 \\
\hline Working with clients with medical conditions & 52 & 47 & 1 \\
\hline Working with other substance abuse & 49 & 48 & 3 \\
\hline Programme administration & 49 & 46 & 5 \\
\hline Community outreach & 46 & 50 & 4 \\
\hline Working with the mentally ill & 39 & 55 & 6 \\
\hline $\begin{array}{l}\text { Participating in the professional development of other } \\
\text { cessation providers }\end{array}$ & 24 & 60 & 16 \\
\hline
\end{tabular}

^Based on 103 total responses

standards consistent with the AHCPR (currently AHRQ) clinical practice guideline and the TTS responsibilities listed in box 1 . While certification cannot ensure that providers deliver evidence based treatment, it does require training in these standards of practice and demonstration of their ability to provide care consistent with the AHRQ national practice guideline through the certification's evaluation protocol. A code of ethics to which all TTSs would be expected to adhere also was developed to complement and support the professional standards of practice. Using the competencies and skill sets that emerged during the role definition study, the following modules were developed and became part of the TTS comprehensive, competency based pilot training curriculum: nicotine dependence-setting the stage (an overview of tobacco, addictions and stages of change); the biology and pharmacology of nicotine dependence; counselling theory and practice; treatment strategies; intake, assessment and treatment planning; group counselling techniques; working with high risk populations (comorbidity, medical conditions); and cross cultural competency. Additional topics, including community outreach, marketing, programme management and evaluation, and professional development were identified as topics to be included in a continuing education programme.

A pilot training programme was held in the spring and fall of 1999. One hundred and thirty tobacco treatment providers identified during our formative research were invited by letter to participate. In an effort to test the appropriateness of the training for a wide variety of health professionals who could potentially provide intensive tobacco treatment services, additional invitations were selectively sent out to school health nurses, substance abuse providers, and mental health counsellors. Sixty three applications were received for 24 training slots. In order for trainees to represent the diversity of MTCP and the state, individuals were selected on the basis of their discipline and professional background, the type of healthcare organisation they represented, the region within Massachusetts where they work, and years working in the tobacco treatment field. Trainees were asked to commit to nine full days of training plus be part of the extensive programme evaluation which included homework assignments, course evaluations, a final exam, and presentation of a written case study to a review board. Passing the latter two evaluation components was required for the granting of TTS certification to the pilot participants.

Before participation in the pilot training programme, participants completed a 33 item pretest based on learning objectives for each of the training modules. The mean score was 16.6 out of a possible $33(50 \%)$. The mean score for the post test was $23.1(70 \%)$. A more complete final exam, consisting of an additional 67 items which were reflective of the material emphasised in the training sessions, produced a mean score of 59.2 out of a possible 67 points, or $88 \%$ correct. In addition, in written evaluations by the participants of the quality of the training programme and how well they believed it prepared them for their work as a TTS, $77 \%$ of the participants rated the course objectives as being very relevant to their work as a tobacco treatment specialist; $63 \%$ reported that their ability to provide effective tobacco treatment services would improve a great deal as a result of this training, while another $31 \%$ reported that their ability would be somewhat improved. Based on the feedback provided by participants and instructors, refinements were made in course content and sequencing was modified. These revisions are reflected in the final training programme described below.

\section{Massachusetts TTS training and certification programme}

Based on the formative research previously described, extensive input from the certification steering committee and from evaluation of and input from the pilot training programme, the training and certification programme was finalised in the winter of 1999 . However, both the process of programme development and ongoing programme modification will remain flexible in order to be responsive to the changing needs and demographics of tobacco users, tobacco treatment providers, and insurers.

The following now forms the basis for the Massachusetts TTS training and certification programme:

1. The training course entails a basic two day training, an intensive six day core certification training, and a set of required continuing education courses following certification. The basic course, entitled "Basic skills for working with smokers", is open to health professionals who encounter tobacco users in the course of their work, regardless of interest in pursuing certifi- 
cation. This course covers the public health perspective on tobacco, health consequences of smoking, addiction theory, use of pharmacotherapy, stages of change model, how to conduct the 5As intervention, and counselling skills for motivating tobacco users. The six day core certification training provides intensive instruction in the biology and pharmacology of nicotine dependence, counselling practice and theory, treatment strategies, intake, assessment and treatment planning, and working with high risk populations. Both the basic and core certification training courses emphasise the application of evidence based practice standards. Required continuing education courses, including programmes on cultural competency, marketing, and group and advanced counselling skills, will be offered periodically.

2. All TTSs need to complete both portions of the training programme (basic and core courses) and have 2000 hours of experience in tobacco treatment before applying for certification. Although training can begin at any time, an individual needs to accumulate 2000 hours before undergoing final review. The steering committee determined that 2000 hours, which is the equivalent of one year of full time experience, was sufficient as a prerequisite for obtaining certification.

3. A two step evaluation of the tobacco treatment knowledge and skills of a potential certification applicant will be used: (a) Written exam upon completion of training to demonstrate acquisition of knowledge; (b) Case study submitted to a review committee and defended orally to demonstrate integration of knowledge, skills and experience.

4. An intensive clinical practice seminar will be offered to TTSs who need to improve their clinical tobacco treatment skills. This seminar will be led by a trained, certified TTS.

5. TTS certification will be renewed every two years with a total of 20 continuing education units (CEUs) required during this period. There will be flexibility in how CEUs are acquired, as many TTSs are certified in other fields that also require CEUs.

6. Continuing education courses will be offered on a regular basis. In addition to offering courses on special topics, continuing education courses will be used to periodically update TTSs on new information regarding nicotine dependence and changes made to evidence based standards of practice, including new cognitivebehavioural and pharmacologic interventions found to be effective in the treatment of nicotine dependence.

7. There will be no grandfathering clause. All TTSs will be required to demonstrate proficiency in the required skills. Consideration is being given to testing out of various modules in the future.

8. The University of Massachusetts Medical School will serve as the certifying body and will be responsible for coordinating and delivering the training courses, conducting the final review process, granting certification, and maintaining a TTS tracking system.

\section{Discussion}

Most established health professions offer or require credentialing beyond an entry level degree. ${ }^{20}$ Credentialing of a particular vocation establishes common standards of practice, encourages continuing professional development, and promotes a sense of professionalism within the discipline. There are three credentialing options: accreditation, which credentials an entire programme; licensure, in which a state agency grants permission to an individual to practice a particular profession; and certification, in which a professional organisation recognises an individual who has met a set of predetermined standards. ${ }^{20}$ The formative work conducted in this project indicated support for the development of a TTS training and certification programme, and provided recommendations for the content, structure, and administration of such a programme in Massachusetts.

Treatment delivered by the certified TTS is not intended to replace the brief intervention delivered by clinicians in the regular course of treating their patients. It is meant to enhance and provide greater access to treatment for tobacco users needing more intensive assistance and follow up. And while intensive training and certification is not needed for these providers, there is support for the need for providers who deliver brief intervention to participate in brief (1-2 hours) training ${ }^{2122}$ so that they can meet the standards of practice as laid out by the AHRQ clinical practice guideline for smoking cessation. ${ }^{6}$ In addition to brief clinician delivered intervention and more moderate to intensive treatment, a comprehensive stepped care approach suggested by Abrams and colleagues ${ }^{8}$ recommends a third level of clinical need, that of the complicated smoker who may be, for example, alcohol dependent or clinically depressed. This tobacco user may need to be referred to a clinical psychologist, psychiatrist or licensed alcohol/drug addiction and mental health provider for more specialised assistance. The TTS would not replace the provider who delivers brief intervention or the specialised masters or doctoral level provider. All three levels of treatment are needed to maximise access, quality, and cost effectiveness of treatment and to match the intensity of treatment to the complexity of the tobacco user's needs (table 5).

As certification in Massachusetts is pursued, an important question is whether it will improve the quality of tobacco treatment care provided to tobacco users. In a review of the literature on this topic, no data were found to indicate that certification improves quality of care. However, there are data demonstrating that training providers in smoking treatment improves treatment skills ${ }^{22}{ }^{23}$ which in turn improves patient outcomes. ${ }^{41}{ }^{23}$ While certification may not directly affect skills, it encourages individuals to receive intensive, evidence based training and continue to keep abreast of new treatments through ongoing CEU requirements. Research to investigate the effect of certification on quality of care and on 
Table 5 Levels of tobacco treatment: providers, interventions, training, and certifications needs

\begin{tabular}{|c|c|c|c|c|}
\hline $\begin{array}{l}\text { Complexity and intensity } \\
\text { of treatment needed }\end{array}$ & Venue/where & Provider & Intervention & Training needs \\
\hline Minimal & $\begin{array}{l}\text { Routine contact with } \\
\text { healthcare system }\end{array}$ & $\begin{array}{l}\text { Physicians, nurses, } \\
\text { other healthcare } \\
\text { providers }\end{array}$ & $\begin{array}{l}\text { Brief 5As (AHRQ } \\
\text { clinical practice } \\
\text { guideline for clinicians) }\end{array}$ & $\begin{array}{l}1-2 \text { hour provider } \\
\text { training } \\
\text { Office systems }\end{array}$ \\
\hline Moderate & $\begin{array}{l}\text { Community health } \\
\text { centres, hospitals, } \\
\text { healthcare and social } \\
\text { service agencies }\end{array}$ & $\begin{array}{l}\text { Tobacco treatment } \\
\text { specialists (TTSs) }\end{array}$ & $\begin{array}{l}\text { Intensive with follow up } \\
\text { (AHRQ clinical practice } \\
\text { guideline for specialists) }\end{array}$ & $\begin{array}{l}2 \text { day basic skills } \\
\text { course and } 6 \text { day } \\
\text { certification course }\end{array}$ \\
\hline $\begin{array}{l}\text { Complex/intensive } \\
\text { (co-morbidity) }\end{array}$ & $\begin{array}{l}\text { Alcohol and drug } \\
\text { addiction treatment } \\
\text { centres, mental health } \\
\text { settings }\end{array}$ & $\begin{array}{l}\text { PhDs, physicians, or } \\
\text { licensed alcohol/drug } \\
\text { addiction and mental } \\
\text { health providers }\end{array}$ & $\begin{array}{l}\text { Intensive plus } \\
\text { alcohol/drug abuse or } \\
\text { mental health treatment }\end{array}$ & $\begin{array}{l}\text { Specialised skills } \\
\text { course }\end{array}$ \\
\hline
\end{tabular}

treatment outcomes is recommended to address this critical issue.

Any state considering certification will need to address the administration and management of such a programme. Management can be a time consuming activity which requires initial funding but can eventually become self supporting through training, examination, and licensing fees. In Massachusetts this responsibility currently resides within the Division of Preventive and Behavioural Medicine in the University of Massachusetts Medical School, with support from the medical school's continuing education department which manages other similar programmes. The starting funds were provided through the MTCP with the expectation that the training and certification programme will become self supporting. In states where funds are not initially made available for the development and management of this important public health programme, start-up funds will need to be obtained until the programme can become self sufficient.

The conclusions drawn from the formative research and the subsequent decision that a certification programme was feasible and desirable for TTSs in Massachusetts needs to be considered in the context of a number of limitations to the research conducted. This research used a qualitative research methodology. It was not possible to identify and interview all national and local experts. Only individuals involved in the delivery of tobacco treatment and health policy were included and it did not involve insurers, health plan administrators and others involved in the larger system of health care. Had different experts been interviewed, different opinions regarding the questions asked may have been provided and different conclusions may have been drawn.

There are many questions about TTS training and certification which remain unanswered and require more rigorous research. For instance, what is the impact of TTS certification on the accessibility and quality of tobacco treatment provided to tobacco users? Will certification restrict the provision of brief treatment by other healthcare professionals during the course of routine care? Are certified TTSs more likely to provide evidence based tobacco treatment than non-certified providers? Who should be identified as providers of tobacco treatment services for the purposes of training and certification? Should individuals who conduct a programme once a year or indi- viduals who use only hypnosis or acupuncture in treating nicotine dependence be included? Who should be responsible for determining the core competencies for certification, developing the evaluation measures for certification, and administering the certification programme? What forms should training take, and who should be responsible for offering and updating it? Are different levels of certification needed to meet the varied needs of the tobacco using population and health professionals caring for them? The University of Massachusetts Medical School has received funding to investigate factors associated with tobacco treatment programme implementation within community health settings (CHSs) funded by MTCP, as measured by the quantity of tobacco treatment services provided, by the CHSs, quality of services provided, reach of services, and implementation of tobacco treatment related systems to support the services within the CHS. This study will provide the opportunity to begin addressing these questions.

Lastly, the question arises as to whether a national certification programme should be developed. A national programme would ensure consistency between states in terms of practice standards, content of TTS training, and expected TTS competencies, and there would be reciprocity between states to accommodate relocating TTSs. Potential third party reimbursement is another important consideration. A national certification with evidence based standards of practice could become the framework within which it may become possible to bill for tobacco treatment services delivered. The issue of developing a national training and certification programme presents the challenges of: designing a "one size fits all" programme that meets the needs of individual states; fiscal concerns pertaining to levels of state and national funding to support such a programme; and the logistical difficulties of administering a national certification programme. Another option would be a combination national/state model where core competencies, evidence based standards of practice, and a training curriculum are developed on a national basis. States could then deliver the training according to these guidelines, adapting the training programme to the special needs of the state and its residents, and would be responsible for setting up a certification system feasible for that state.

The purpose of this paper is to present the steps taken in one state, Massachusetts, to 
develop a training and certification programme for TTSs. It is hoped it will contribute to a national dialogue on the potential advantages, disadvantages, and structure of a training and certification system for persons delivering tobacco treatment services.

Support for this work was by funding from the Massachusetts Department of Public Health (MDPH) Tobacco Control Program, the American Stop Smoking Intervention Study (ASSIST), funded by the National Cancer Institute, Division of Cancer Prevention, through a contract with the MDPH, and Cancer Prevention, through a contract with the MDPH, and Comprehensive State-Based Tobacco Use Prevention and Control Programs, funded by the National Centers for Disease Control and Prevention through a contract with the MDPH.
The authors would like to acknowledge Leslie Davis Weintraub The authors would like to acknowledge Leslie Davis Weintraub
and Lauren Toolin for their contributions to the formative research process.

1 Bartlett J, Miller L, Rice D, et al. Medical-care expenditures attributable to cigarette smoking-United States, 1993 MMWR Morb Mortal Wkly Rep 1994;43:469-72.

$2 \mathrm{CDC}$ and Prevention. Cigarette smoking among adultsUnited States, 1997. MMWR Morb Mortal Wkly Rep 1999;48:993-6.

$3 \mathrm{CDC}$ and Prevention. Use of smokeless tobacco among adults-United States, 1991. MMWR Morb Mortal Wkly Rep 1993;42:263-6.

4 Fiore MC, Bailey WC, Cohen SJ, et al. Smoking cessation. Clinical Practice Guideline No 18. Rockville, Maryland: US Department of Health and Human Services, Public Health Service, Agency for Health Care Policy and Research, April 1996. (AHCPR Publication No 960692.); < http://text.nlm.nih.gov>.

5 Centers for Disease Control and Prevention. Best practices for comprehensive tobacco control programs-August 1999. for comprehensive tobacco control programs-August 1999. Atlanta Goergia: US Department of Health and Human Services, Centers for Disease Control and Prevention,
National Center for Chronic Disease Prevention and Health Promotion, Office on Smoking and Health, August 1999.

6 Fiore MC, Bailey WC, Cohen SJ, et al. Treating tobacco use and dependence. Clinical Practice Guideline. Rockville, Maryland: US Depantment of Health and Human Services. Public Health Service, 2000.

7 Center for the Advancement of Health. Dependence in the US: ad hoc group findings and recommendations. February 1998. www.cfah.org
8 Abrams D, Orleans C, Niaura R, et al. Integrating individual and public health perspectives for treatment of tobacco dependence under managed health care: a combined stepped care and matching model. Ann Behav Med 1996; 18:290-304.

9 Brooks DK, Gerstein, L. Counselor credentialing and interprofessional collaboration. Fournal of Counseling and Development 1990;68:477-84.

10 Girvan JT. The case for school health educators becoming certified health education specialists. Fournal of Health Education 1993;24:296-8.

11 Kolpack R. Credentialing alcoholism counselors. Alcoholism Treatment Quarterly 1992;9(3-4):97-112.

12 Leahy M, Holt E. Certification in rehabilitation counseling. fournal of Applied Rehabilitation Counseling 1993;24:5-9.

13 McLeod B, Benoit M. An overview of the Canadian diabetes educator certification program. Beta Release 1992; 16:126-9.

14 Milgram GG. Certification of alcoholism/drug counselors. Psychology of Addictive Behaviors 1990;4:40-2.

15 Myers JE. From "Forgotten and ignored" to standards and certification: gerontological counseling comes of age. fournal of Counseling and Development 1995;74:143-9.

16 Nolte AE, Hamburg, MV. Development of national certification for health education specialists. Fournal of Health Education 1993;24:263-8.

17 Page RC, Bailey JB. Addictions counseling certification: an emerging counseling specialty. Fournal of Counseling and Development 1995;74:167-71.

18 Schreiner B, Norman J. Report from the NCBDE: a summary of the certification process for 1991 and 1992 . Diabetes Educator 1993;19:233-5.

19 Syzmanski EM, Linkowski DC, Leahy M, et al. Validation of rehabilitation counseling accreditation and certification knowledge areas: Methodology and initial results. Fournal of Applied Rehabilitation Counseling 1993;24:24-31.

20 National Commission for Health Education Credentialing Inc. The CHES Bulletin, Spring 1998;9:3.

21 Ockene J, Kristeller J, Goldberg R, et al. Increasing the efficacy of physician-delivered smoking intervention: a randomized clinical trial. F Gen Intern Med 1991;6:1-8.

22 Ockene J, Quirk M, Goldberg R, et al. A residents' training program for the development of smoking intervention skills. Arch Int Med 1988;148:1039-45.

23 Lindsay E, Wilson D, Best A, et al. A randomized trial of physician training for smoking cessation. Am 7 Health Prom 1989;3:11-18.

\section{Invitation to Delegates}

\section{6th European Forum on Quality Improvement in Health Care Thursday 29-Saturday 31 March 2001, Bologna, Italy}

For full information, contact BMA/BMJ Conference Unit, BMA House, Tavistock Square, London WC1H 9JP UK. Tel +44 (0) 207383 6409; fax: +44 (0) 207383 6869; email: quality@bma.org.uk

Bookmark our website for full information: www.quality.bmjpg.com 